\title{
Preparation of Antibacterial Color-Coated Steel Sheets
}

\author{
Guoliang Li, Bing Peng, Liyuan Chai, Si Wan, and Lei Jiang \\ School of Metallurgical Science and Engineering, Central South University, Changsha 410083, China \\ Correspondence should be addressed to Bing Peng, pb@mail.csu.edu.cn
}

Received 15 September 2011; Revised 23 January 2012; Accepted 23 January 2012

Academic Editor: Gongxuan Lu

Copyright () 2012 Guoliang Li et al. This is an open access article distributed under the Creative Commons Attribution License, which permits unrestricted use, distribution, and reproduction in any medium, provided the original work is properly cited.

\begin{abstract}
A simple method to fabricate antibacterial color-coated steel sheet was presented. The Ag-loaded $\mathrm{TiO}_{2}$ was well dispersed in steel coil coating coupled with some special additives, such as plasticizer, wetting dispersant, and flow agent, and finally became the part of coil coating without any negative influence on the properties of final products. The best process parameters were obtained by substantive trial experiments. Ag-loaded $\mathrm{TiO}_{2}$ with the addition of $2 \%(w / w)$ in steel coil coating not only improved antibacterial efficiency of the antibacterial color-coated sheet by reaching $99.99 \%$, but also greatly increased the degradation percentage of methyl orange to $88 \%$ without decreasing physical properties. The antibacterial color-coated sheets are expected to be used as antimicrobial products in the construction industry considering its low cost and high effectiveness in inhibiting the growth of bacteria.
\end{abstract}

\section{Introduction}

The menace of infection caused awareness around the world by the suddenly globally spreading epidemic disease, such as avian influenza [1], SARS, H1N1, and other unexpected multiplication of germs or other bacteria that pose serious health problems $[2,3]$. Great deals of antibacterial products appeared in the cases of antibacterial ceramics [4-7], antibacterial glasses [8-10], antibacterial textiles [11-13], antibacterial plastics [14-16], antibacterial stainless steels [17-20], and so forth. These applications mainly involve the methods of adding antibacterial agents into the overall substrate, modifying the surface of substrate, or directly coating the antibacterial agents. However, the development of antibacterial products in a wide range of areas was still hindered due to the low effective utilization rate of the antibacterial agents, the high cost, and the poor binding force, which existed between antibacterial agents and the substrates restrict. In this paper, the antibacterial agent was firstly poured into the coil coating before being made into the antibacterial color-coated sheet. Sequent research findings demonstrated that antibacterial agents presented a comfortable dispersive distribution on the surface of colorcoated sheet, which could remarkably reduce the cost by attributing to the less addition of antibacterial agents and the simple manufacturing technological process. It was also found that the binding force among the antibacterial agents and substrate got much stronger than ever due to the integration of antibacterial agents into the coil coating.

Served as one category of antibacterial agent, titanium dioxide is the most preferred material to be served as pigment. Unfortunately, the antimicrobial activity of pure $\mathrm{TiO}_{2}$ is merely valid when it is irradiated under UV light. In addition, the low electron transfer rate to oxygen and high recombination rate of electron-hole employed in UV light impose further limits to the effective photocatalytic sterilization rate of $\mathrm{TiO}_{2}$ [21-23]. These drawbacks strongly restricted the practical applications of $\mathrm{TiO}_{2}$ as an effective and promising antimicrobial material. Silver (including Ag ions and $\mathrm{Ag}$ nanoparticles) is a well-known and effective inorganic antimicrobial material that has been applied in many fields. However, the high-cost and dark color are two notable obstacles during its applications as large-scale antimicrobial coatings [24-26]. Nevertheless, Ag can act as both an antimicrobial auxiliary agent and a sink for electrons and redox catalyst that may enhance the overall photooxidation ability of $\mathrm{TiO}_{2}$ [27-30]. Thus, it is reasonable and rational to combine $\mathrm{Ag}$ with $\mathrm{TiO}_{2}$ during antimicrobial coatings production.

This study focused on the manufacture of antibacterial color-coated sheet using Ag-loaded $\mathrm{TO}_{2}$ as antibacterial agent. The antibacterial agent was firstly poured into steel 


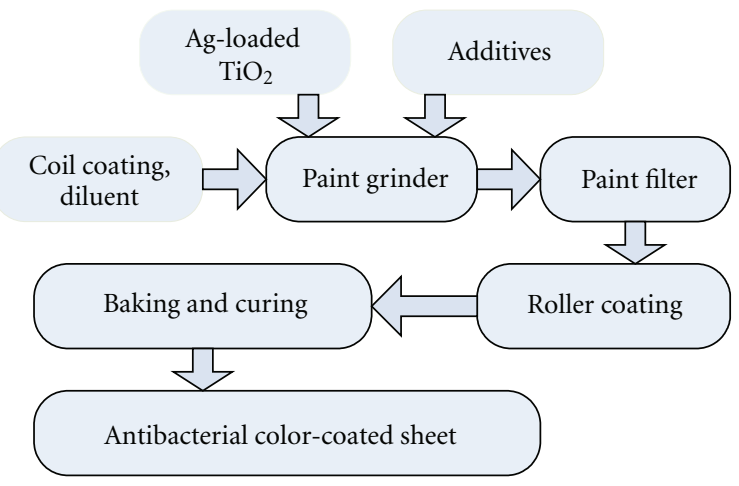

Figure 1: Preparation flowsheet of antibacterial color-coated sheet.

coil coating with some additives and made into the antibacterial coil coating. And then, the antibacterial color-coated sheet was manufactured in a normal process. It delivered a technology of less addition of antibacterial agents and simple procedure.

\section{Experimental}

2.1. Materials. Ag-loaded $\mathrm{TiO}_{2}$ was purchased from Jingui Group (Chenzhou, China). The grain size was $48 \mathrm{~nm}$ and the Ag particle size was $10 \mathrm{~nm}$. Coil coatings (including polyester topcoat and epoxy priming paint) and diluents (the main components were ethyl acetate, butyl acetate, benzene, toluene, acetone, ethanol, butanol, etc.) were provided by Center Group (Changshu, China). The additives including plasticizer, wetting dispersant, and flow agents were purchased from Yongyan Ltd. (Shanghai, China).

2.2. Preparative Method of Antibacterial Color-Coated Sheet. The preparative process of antibacterial color-coated steel plate is shown in Figure 1. A certain amount of coil coatings, coil coating diluents, silver-loaded titanium dioxide, and some additives including plasticizer, wetting dispersant, and flow agents were added into the paint grinder running in high speed, and then filtered through the paint filter. Finally, the color-coated steel plate was achieved by roll coating, baking and curing.

The Ag-loaded $\mathrm{TiO}_{2}$ used in this study was produced by Jingui Group using the technological process developed in our previous studies [31-35].

2.3. Antibacterial Properties Testing. Antibacterial properties of products were tested according to "Antibacterial Coating-Antibacterial Performance Test Method, the appendix A of "the People's Republic of China Chemical Standard HG/T 3950-2007”. In the tests, nutrient agar media (Luria Broth, LB) was prepared in water by mixing tryptone, $\mathrm{NaCl}$, agarose gel powder and yeast extract in the volume percent of $1 \%, 0.5 \%, 1.5 \%$, and $0.5 \%$ to total of media, respectively. The mixture was put into a conical flask and autoclaved for $45 \mathrm{~min}$ at $120^{\circ} \mathrm{C}$. The conical flask was kept in room temperature for $2 \mathrm{~h}$ for cooling and then poured into separate
Petri dishes. A $5 \mathrm{~cm} \times 5 \mathrm{~cm}$ sample was cut from the antibacterial color-coated sheets for bacterial culture and the surface of all samples was cleaned with absolute ethanol soaked tissue paper before antibacterial test. The samples were placed in separate Petri dishes on top of the predeposited LB. A clean soda-lime glass piece was used as a control sample. After placing the antibacterial color-coated sheets samples, a thin layer of LB was further deposited on top. These plates were kept for $1 \mathrm{~h}$ for complete gelation of the agar, and after that quantitative solution of $E$. coli was evenly spread over each gel plate in the respective Petri dishes. The plates were incubated for 24 hours to allow the completion of bacterial growth. The bacterial colonies formed in each plate were observed and the bacterial number on each sample was counted with colony counting method. The antibacterial efficiency of the color-coated sheet was calculated in

$$
\text { Antibacterial efficiency }=\frac{A_{0}-A}{A_{0}},
$$

where $A_{0}$ and $A$ are the antibacterial number of the control sample and antibacterial color-coated sheet sample, respectively.

2.4. Photocatalysis Properties. The methyl orange solution with 3 of $\mathrm{pH}$ value was poured into the culture. The photocatalytic activity of the antibacterial color-coated sheet was evaluated on the degradation of methyl orange in an aqueous solution under illumination of UV light (mercury vapor lamp, $40 \mathrm{~W}, 40 \mathrm{~cm}$ long, predominant wavelength $253.7 \mathrm{~nm}$ ) in a photoreactor system. The degradation of methyl orange was calculated in

$$
\text { Degradation }=\frac{B_{0}-B}{B_{0}},
$$

where $B_{0}$ and $B$ are the absorbance of the primal and remaining methyl orange, respectively. The absorbance was measured with UV/vis spectrophotometer (UV-2450, Japan).

2.5. Duration Properties. The antibacterial color-coated sheet was made of the white gray coil coating with $2 \%$ silver-loaded titanium dioxide, cutting into $5 \mathrm{~cm} \times 5 \mathrm{~cm}$ pieces. Forty-five pieces were placed into the $\varphi 9 \mathrm{~cm}$ culture dish, respectively, with three parallel samples each day. Then each culture dish was poured $30 \mathrm{~mL}$ ultra-pure water, and sampled every day. The silver content in the water and the antibacterial properties of the sheets would be tested.

\section{Results and Discuss}

3.1. Antibacterial Properties. Addition of antibacterial agent and effective utilization rate are key factors influencing on antibacterial properties of the color-coated sheet. The more antibacterial agents used, the higher antibacterial efficiency obtained, but the cost also increased thereupon. The best dose should satisfy antibacterial requirement and low cost. Ag-loaded $\mathrm{TiO}_{2}$ should be highly dispersed under stirring and function of additives to get well compatibility with coil 
TABLE 1: Effect of agent amount on antibacterial property of color-coated steel.

\begin{tabular}{lcccccc}
\hline The dose of Ag/TiO $/$ /wt\% & 0 & 1 & 2 & 3 & 4 \\
\hline Bacterial count of $1 \# / \mathrm{cfu}$ & $1.88 \times 10^{6}$ & $2.40 \times 10^{5}$ & 172 & 29 & $<20$ & $>20$ \\
Antibacterial efficiency/\% & - & 87.23 & $>99.99$ & $>99.99$ & $>99.99$ & $>99.99$ \\
Bacterial count of $2 \# / \mathrm{cfu}$ & $1.86 \times 10^{6}$ & $2.36 \times 10^{5}$ & 166 & 27 & $<20$ & $>20$ \\
Antibacterial efficiency/\% & - & 87.31 & $>99.99$ & $>99.99$ & $>99.99$ & $>20$ \\
Bacterial count of 3\#/cfu & $1.91 \times 10^{6}$ & $2.48 \times 10^{5}$ & 180 & 35 & $>20$ \\
Antibacterial efficiency/\% & - & 87.02 & $>99.99$ & $>99.99$ & $>99.99$ & $>99.99$ \\
Average antibacterial efficiency/\% & - & 87.19 & $>99.99$ & $>99.99$ & $>99.99$ & $>99.99$ \\
\hline
\end{tabular}

coating. So, the rotation speed and stirring time are considered.

Table 1 shows the effects of different antibacterial agent dosages on the antibacterial properties of color-coated sheet.

As from Table 1, the antibacterial properties increased with the increase of addition of antibacterial agents. The antibacterial efficiency reached about $87 \%$ when $1 \%(\mathrm{wt})$ of Ag-loaded $\mathrm{TiO}_{2}$ was added. Obviously, the antibacterial efficiency reached $99.99 \%$ when the antibacterial agents addition was higher than $2 \%$. This could be ascribed to the reactive oxygen antibacterial mechanism. In the presence of water and oxygen, the antibacterial agents containing $\mathrm{TiO}_{2}$ can adsorb water and oxide, producing $\mathrm{HO}^{*}$ with high oxidative and reactive capacity. $\mathrm{HO}^{*}$ can infiltrate and destruct coenzyme $\mathrm{A}$ and also degrade endotoxin, protein lipids and mineralize into $\mathrm{CO}_{2}$ through particles on the cell surface binding of the hydroxyl groups. $\mathrm{Ag}^{+}$ in the antibacterial agents can be firmly attached to the bacteria, and further penetrate into the bacterial cell wall when contacting the negatively charged cell membrane. This responds to $\mathrm{OH}$ in bacteria and results in bacterial proteins coagulation, cell synthesize enzyme activity destruction, and therefore, loss of reproduce ability and death. Besides, $\mathrm{Ag}^{+}$ can also destroy bacteria electronic transmission system, respiratory system, and mass transport system for killing bacteria. Silver-loaded titanium dioxide agents have the advantages of both above at high temperature, high security, long-term sterilization, and high antibacterial property even in dark condition. Therefore, the $2 \%$ dosage of silver-loaded titanium dioxide in coil coating is determined.

Silver-loaded titanium dioxide was added to the mixture of paint at high speed, and then an original speed. The effects of different rotation speeds on the fineness of the coil coating and gloss of the color-coated steel sheet were investigated.

As seen from Figures 2 and 3, the fineness of the coating decreased and the gloss of color sheet increased gradually with the increase of speed. The fineness of coating is the range of $10-20 \mu \mathrm{m}$ and the gloss $35 \pm 5$ according to "evaluation method of dispersion of pigments." The fineness of coating is about $19 \mu \mathrm{m}$ and the gloss approximately 32 under speed $4000 \mathrm{r} / \mathrm{min}$, both of which meet the required standards. Antibacterial agents dispersed in the coil coating passes through three processes, namely, wetting, grinding, and dispersion and stability. Wetting is defined as the solvent taking the place of the air and water on the surface of paint. Solvent-based paint is not a problem as the surface tension

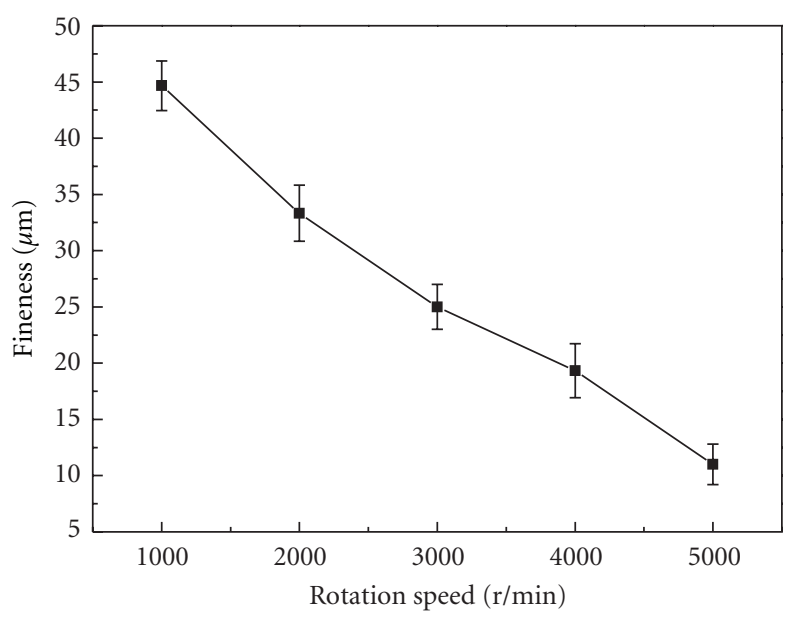

FigURE 2: Effect of stirring speed on fineness of particles.

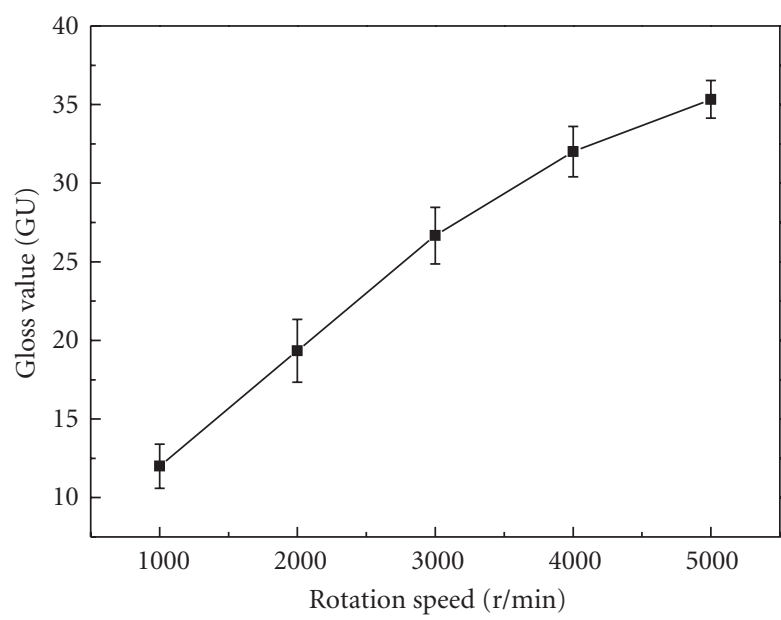

Figure 3: Effect of stirring speed on gloss value.

of paint is always lower than that of the general. The silverloaded titanium dioxide is a nanopowder, but the particles of antibacterial agents would get together due to van der waals force. Therefore, it is required to redisperse under shearing or impact forces.

When the shear rate $(D)$ is constant, the shear force $(\tau)$ and viscosity $(\eta)$ is proportional as

$$
\tau=D \eta
$$




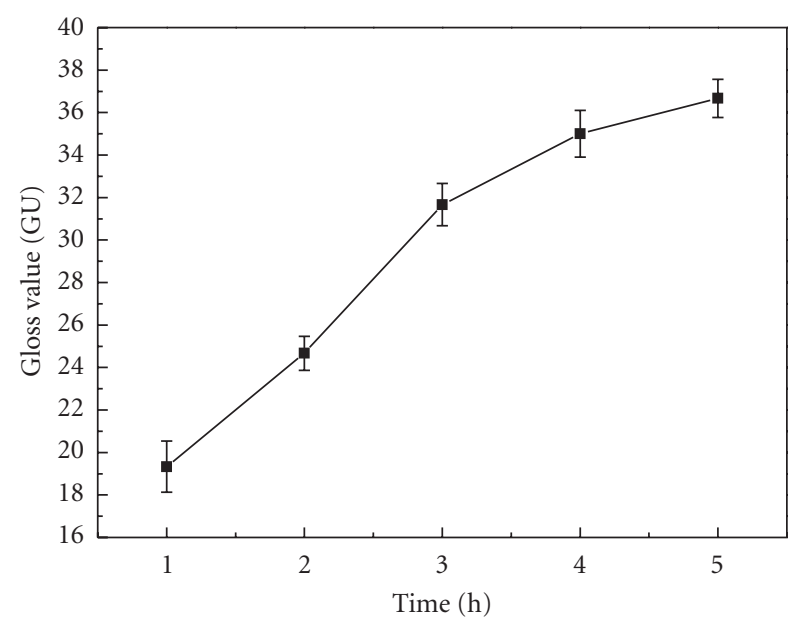

FIgURE 4: Effect of stirring time on fineness of coil coating.

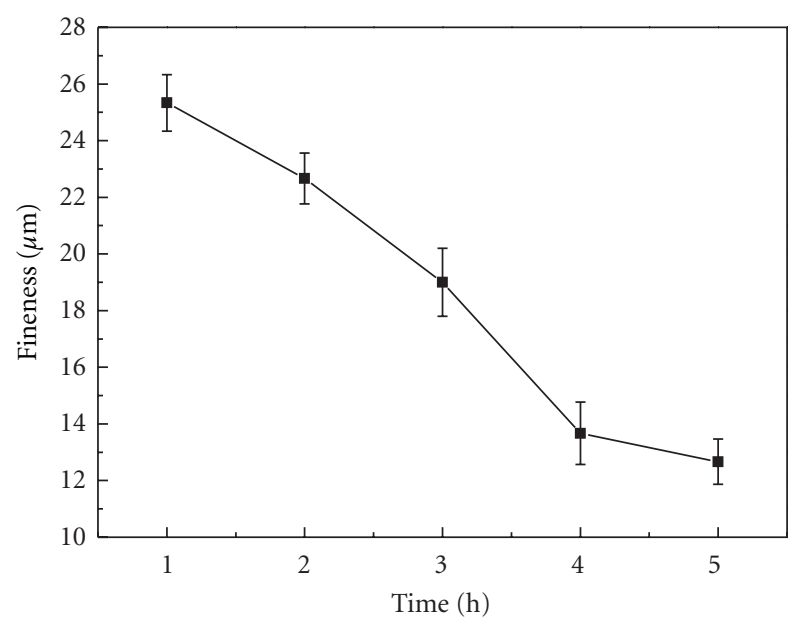

FIGURE 5: Effect of stirring time on gloss of coil coating.

The higher the speed, the greater the shearing force under certain viscosity, which is helpful for the grinding. In summary, silver-loaded titanium dioxide is added to the coil coating under the speed of $4000 \mathrm{r} / \mathrm{min}$.

The effects of stirring time on fineness of the coil coating and gloss of the color-coated sheet were studied under $4000 \mathrm{r} / \mathrm{min}$ of rotation speed after adding silver-loaded titanium dioxide to the coil coating.

Figures 4 and 5 show the effects of stirring time on finess and gloss of coil coating. It is evident that the fineness decreased and the gloss improved with the increase of stirring time. The fineness and the gloss were about $19 \mu \mathrm{m}$ and 32, respectively, after stirred for $3 \mathrm{~h}$. Both values reached the pigments and the grinding fineness requirements based on "the evaluation method of dispersion of pigments" mentioned above. Consequently, the final choice of grinding time is $3 \mathrm{~h}$.

The surface morphology of color-coated sheet was observed by using SEM in order to detect the effect of antibacterial agent in the coil coating. SEM analysis results of precoated layer of color-coated sheets with and without Agloaded $\mathrm{TiO}_{2}$ are shown in Figure 6. The coated particles after adding antibacterial agents were well distributed except a small part of the reunion, and the particle sizes were about $10 \mu \mathrm{m}$, which is quite similar to the ordinary color-coated sheet. The results were in accordance with the measurement results and achieved the required fineness. It was indicated that Ag-loaded $\mathrm{TiO}_{2}$ almost became the part of coil coating under the function of additives. There was nearly no difference between ordinary color-coated sheet and antibacterial color-coated sheet in appearance and morphology. This was beneficial to the dispersion of antibacterial agents and the improvement of the antibacterial property.

$\mathrm{Ag}$ in the antibacterial agent plays an important role in antibacterial property. The most distinguished feature of the ordinary color-coated sheet and antibacterial colorcoated sheet lies in the function of silver and titanium dioxide. Although the addition was little, the change of the elements in the ordinary color-coated sheet and antibacterial color-coated sheet should be observed. EDX analysis of color-coated sheet with and without antibacterial agents was undertaken to analyze the change of their elements. The results are showed in Figure 7.

It can be seen from the figures that the elements $\mathrm{Ti}$ and Ag in color-coated sheet adding antibacterial agents appeared as compared to those without adding antibacterial agents. However, the dosage of elements was relatively small so that the increase of elements $\mathrm{Ti}$ and $\mathrm{Ag}$ were not significant. Nonetheless, it also can be indicated that silver-loaded titanium dioxide has been incorporated into the precoated layer of antibacterial color-coated sheet.

3.2. Photocatalysis Properties. Figure 8 shows the methyl orange degradation ability of color-loaded sheet. The concentration of methyl orange decreased with time and came to the equilibrium finally. The speed of degradation is not fast with the degradation efficiency of $25 \%$ in the first $1 \mathrm{~h}$. However, the degradation efficiency reached about $80 \%$ after $2 \mathrm{~h}$. Methyl orange concentration tends to be stable with the degradation efficiency of about $88 \%$ at 4 th hour. In conclusion, the color-coated sheet synthesized in the present study possesses high degradation of methyl orange. The color-coated sheet adding antibacterial agents has the capability of "self-cleaning."

Photocatalytic degradation of methyl orange mechanism is as follows: the valence band electrons of silver-loaded titanium dioxide are excited under UV, then they jump across the forbidden band into the conductive band and form the highly reactive negative-charged electron $\mathrm{e}^{-}$, while producing a corresponding hole $\mathrm{h}^{+}$in the valence band. Then electrons and holes separate and migrate to different positions on the surface of particles and reduction and oxidation happens on the surface of materials. The main reactions are as follows:

$$
\begin{gathered}
\mathrm{OH}^{-}+\mathrm{h}^{+} \longrightarrow \cdot \mathrm{OH} \\
\mathrm{H}_{2} \mathrm{O}+\mathrm{h}^{+} \longrightarrow \cdot \mathrm{OH}+\mathrm{H}^{+} \\
\mathrm{e}^{-}+\mathrm{O}_{2} \longrightarrow \mathrm{O}_{2}{ }^{-}
\end{gathered}
$$




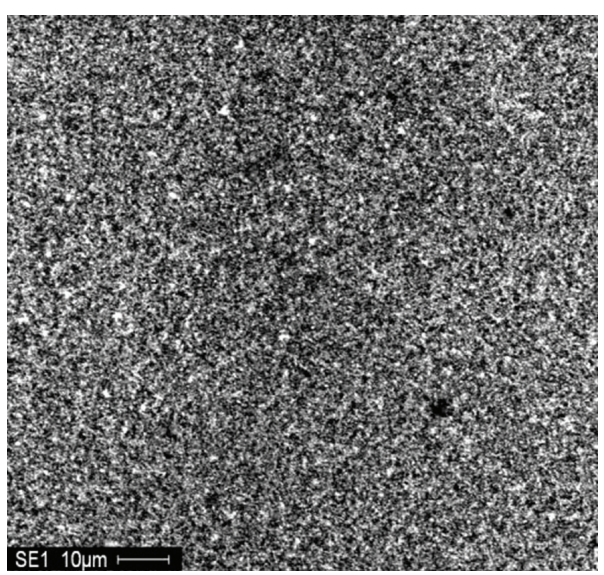

(a)

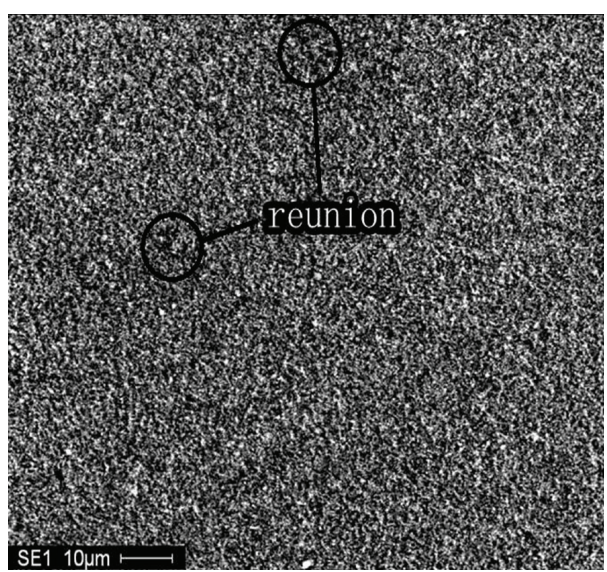

(b)

FIGURE 6: SEM of ordinary color-coated sheet (a) and antibacterial color-coated sheet (b).

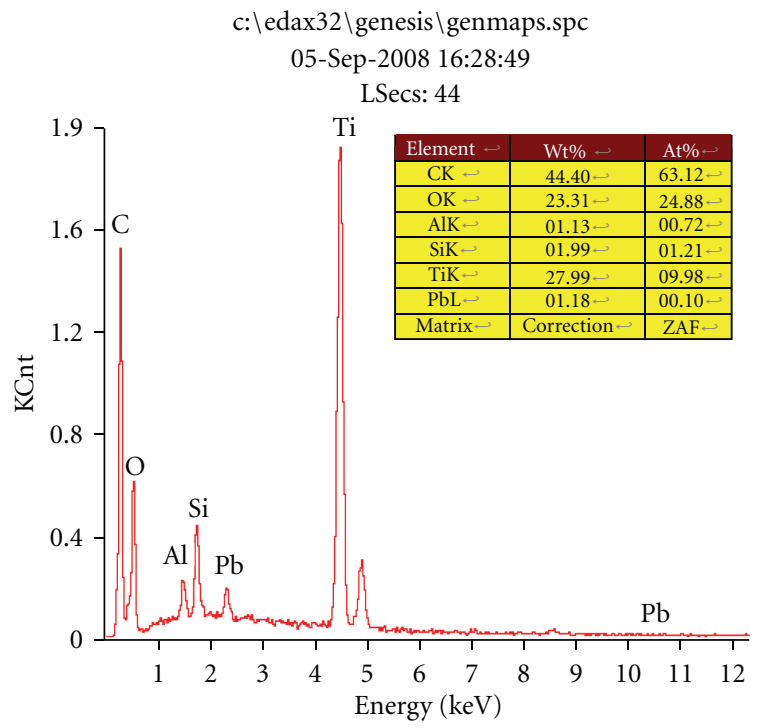

(a)

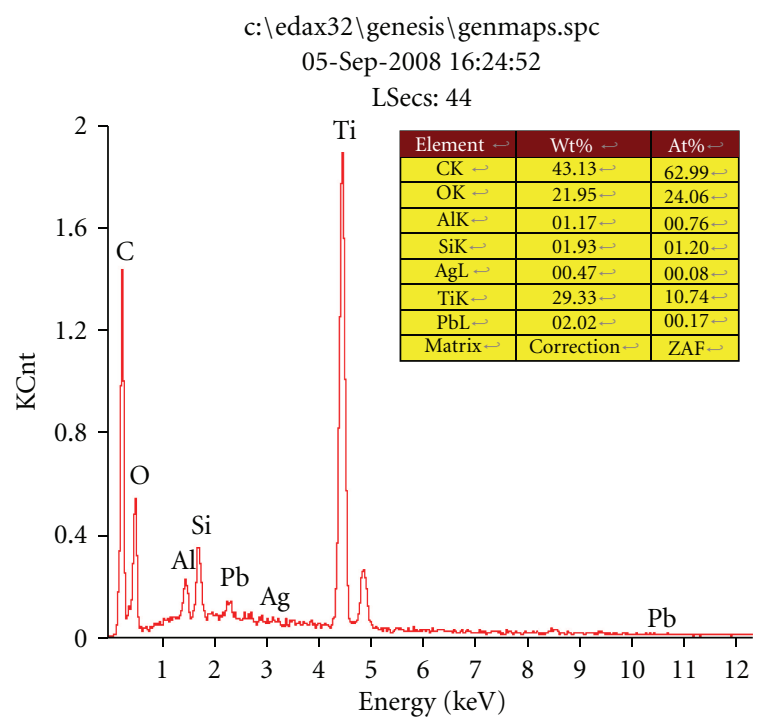

(b)

FIGURE 7: EDX of (a) ordinary color-coated sheet and (b) antibacterial color-coated sheet.

$$
\begin{gathered}
\cdot \mathrm{OH}+\text { organics } \longrightarrow \cdots \longrightarrow \mathrm{CO}_{2}+\mathrm{H}_{2} \mathrm{O} \\
\mathrm{O}_{2}{ }^{-}+\text {organics } \cdots \longrightarrow \mathrm{CO}_{2}+\mathrm{H}_{2} \mathrm{O}
\end{gathered}
$$

3.3. Stability and Duration Properties. The stability of antibacterial coil coating was evaluated using the centrifugation settling time and gravity settling time. The settling time of antibacterial agents is equal to the storage period of antibacterial agents in the coil coating under gravity. The time for appearing $10 \mathrm{~mm}$ supernatant is the centrifugal settling time $t_{C}$. Gravity settling time $t_{G}$ can be calculated by

$$
\frac{t_{G}}{t_{C}}=\frac{4 \pi^{2} R N^{2}}{g}
$$

TABLE 2: Effect of stability of coil coating under non-modified and modified.

\begin{tabular}{lcc}
\hline & Non-modified coil coating & Modified coil coating \\
\hline Time/month & 25.1 & 15.6 \\
\hline
\end{tabular}

As shown in Table 2, the storage period of coil coating is about 2 years without antibacterial agents and 16 months with antibacterial coil coating. The silver-loaded titanium dioxide particles make Brownian motion in the coil coating, which could result in the decline of stability. Flocculation appears under the particles' kinetic energy over the repulsive force when particles contact to each other. Therefore, adding antibacterial agents makes the stability of the coil coating decreased. 
TABLE 3: Results of pilot-scale run and practical application (average values).

\begin{tabular}{|c|c|c|c|c|c|c|c|c|c|c|}
\hline & \multicolumn{4}{|c|}{ Chromatic aberration } & \multirow{2}{*}{ Impact/J } & \multirow{2}{*}{$\begin{array}{l}\text { MEK/ } \\
\text { times }\end{array}$} & \multirow{2}{*}{$\begin{array}{l}\text { Gloss- } \\
\text { iness } /\left(^{\circ}\right)\end{array}$} & \multirow{2}{*}{ T-bend/T } & \multirow{2}{*}{$\begin{array}{l}\text { Film thick- } \\
\text { ness } / \mu \mathrm{m}\end{array}$} & \multirow{2}{*}{$\begin{array}{l}\text { Antibacteria } \\
\text { Efficiency }\end{array}$} \\
\hline & DL & $\mathrm{Da}$ & $\mathrm{Db}$ & $\mathrm{DE}$ & & & & & & \\
\hline Hand sample & 0.09 & 0.06 & -0.10 & 0.21 & 9 & $>100$ & 33 & $3 \mathrm{~T}$ & 14 & $>99.99 \%$ \\
\hline Bulk sample & 0.07 & 0.03 & -0.07 & 0.10 & 9 & $>100$ & 32 & $2 \mathrm{~T}$ & 14 & $>99.99 \%$ \\
\hline $\begin{array}{l}\text { First batch of } \\
\text { commercial } \\
\text { product }\end{array}$ & -0.23 & -0.18 & 0.01 & 0.28 & 9 & $>100$ & 34 & $3 \mathrm{~T}$ & 14 & $>99.99 \%$ \\
\hline $\begin{array}{l}\text { Second batch of } \\
\text { commercial } \\
\text { product }\end{array}$ & -0.09 & -0.11 & 0.06 & 0.16 & 9 & $>100$ & 33 & $3 \mathrm{~T}$ & 14 & $>99.99 \%$ \\
\hline
\end{tabular}

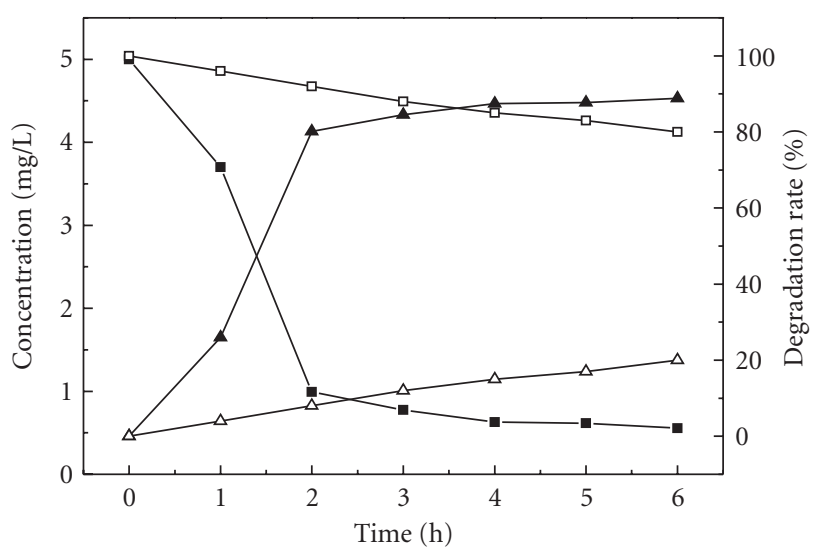

- - Concentration of sample $\quad \rightarrow-$ Concentration of blank $\neg$ Degradation rate of sample $\triangle \backsim$ Degradation rate of blank

FIGURE 8: Photocatalytic degradation ratio of antibacterial colorcoated sheet.

Duration property was characterized by the release of $\mathrm{Ag}^{+}$in the antibacterial color-coated sheet and the antibacterial efficiency after water immersion. The release and antibacterial properties of $\mathrm{Ag}^{+}$in the antibacterial color-coated sheet kept at $3 \mu \mathrm{g} / \mathrm{L}$ and did not change significantly in 15 days. The antibacterial properties of the antibacterial color sheet achieved 99.99\%, and $\mathrm{Ag}^{+}$release was not detected when the sheet was immersed in water. Thus, the duration property of antibacterial color-coated sheet is perfect.

3.4. Pilo-Scalet Run and Practical Application. The physical properties of antibacterial color-coated sheets conducted "Test methods for prepainted GB/T 13448-2006" and the antibacterial property was finished by "Guangdong Detection Center of Microbiology." Random sampling test was carried out on hand sample, bulk sample, and commercial products. The results in Table 3 indicate that the values of terminal products could meet the first class standard according to "Specification for prepainted steel sheet GB/T 12754-2006."

\section{Conclusions}

A simple way to manufacture antibacterial color-coated sheet using Ag-loaded $\mathrm{TiO}_{2}$ is developed. The optimal technical parameters are $2 \%$ of silver-loaded titanium dioxide, $4000 \mathrm{r} / \mathrm{min}$ of stirring speed, $3 \mathrm{~h}$ for stirring time. The silverloaded titanium dioxide is dispersed well in color-coated sheet and the antibacterial efficiency reaches $99.99 \%$. The efficiency of methyl orange degradation reaches $88 \%$ in $4 \mathrm{~h}$. The duration of antibacterial color-coated sheet is long enough. The products of antibacterial color-coated sheet meet the first class standard of prepainted steel sheet and have excellent properties of antibiosis, photocatalysis, and duration.

\section{Acknowledgments}

This study was supported by the National High Technology Research and Development Program of China (2010AA065205), National Science Foundation for Distinguished Young Scholars (50925417), and the Key Project of Science and Technology of Hunan Province (2009FJ1008). All authors would like to give their thanks for the financial support mentioned above.

\section{References}

[1] A. Mills and S. le Hunte, "An overview of semiconductor photocatalysis," Journal of Photochemistry and Photobiology A, vol. 108, no. 1, pp. 1-35, 1997.

[2] T. Matsunaga, R. Tomoda, T. Nakajima, and H. Wake, "Photoelectrochemical sterilization of microbial cells by semiconductor powders," FEMS Microbiology Letters, vol. 29, no. 1-2, pp. 211-214, 1985.

[3] U. Desselberger, "Emerging and re-emerging infectious diseases," Journal of Infection, vol. 40, no. 1, pp. 3-15, 2000.

[4] M. Korroris, C. C. Trapalis, S. Kossionides et al., "RBS and HIRBS studies of nanostructured $\mathrm{AgSiO}_{2}$ sol-gel thin coatings," Nuclear Instruments and Methods in Physics Research $B$, vol. 188, no. 1-4, pp. 67-72, 2002.

[5] M. Catauro, M. G. Raucci, F. de Gaetano, and A. Marotta, "Antibacterial and bioactive silver-containing $\mathrm{Na}_{2} \mathrm{O} \cdot \mathrm{CaO} \cdot 2 \mathrm{SiO}_{2}$ glass prepared by sol-gel method," Journal of Materials Science, vol. 15, no. 7, pp. 831-837, 2004. 
[6] G. Fu, P. S. Vary, and C. T. Lin, "Anatase $\mathrm{TiO}_{2}$ nanocomposites for antimicrobial coatings," Journal of Physical Chemistry B, vol. 109, no. 18, pp. 8889-8898, 2005.

[7] M. Kawashita, S. Tsuneyama, F. Miyaji, T. Kokubo, H. Kozuka, and K. Yamamoto, "Antibacterial silver-containing silica glass prepared by sol-gel method," Biomaterials, vol. 21, no. 4, pp. 393-398, 2000.

[8] A. A. Ahmed, A. A. Ali, D. A. R. Mahmoud, and A. M. ElFiqi, "Study on the preparation and properties of silver-doped phosphate antibacterial glasses," Solid State Sciences, vol. 13, no. 5, pp. 981-992, 2011.

[9] A. Mukhopadhyay, S. Basak, J. K. Das, S. K. Medda, K. Chattopadhyay, and G. De, "Ag- $-\mathrm{TiO}_{2}$ Nanoparticle codoped $\mathrm{SiO}_{2}$ films on $\mathrm{ZrO}_{2}$ barrier-coated glass substrates with antibacterial activity in ambient condition," Applied Materials \& Interfaces, vol. 9, no. 2, pp. 2540-2546, 2010.

[10] S. M. Lee, B. S. Lee, T. G. Byun, and K. C. Song, "Preparation and antibacterial activity of silver-doped organic-inorganic hybrid coatings on glass substrates," Colloids and Surfaces A, vol. 355, no. 1-3, pp. 167-171, 2010.

[11] R. Dastjerdi, M. Montazer, and S. Shahsavan, "A novel technique for producing durable multifunctional textiles using nanocomposite coating," Colloids and Surfaces B, vol. 81, no. 1, pp. 32-41, 2010.

[12] R. Dastjerdi and M. Montazer, "A review on the application of inorganic nano-structured materials in the modification of textiles: focus on anti-microbial properties," Colloids and Surfaces B, vol. 79, no. 1, pp. 5-18, 2010.

[13] M. Montazer, E. Pakdel, and A. Behzadnia, "Novel feature of nano-titanium dioxide on textiles: antifelting and antibacterial wool," Journal of Applied Polymer Science, vol. 121, no. 6, pp. 3407-3413, 2011.

[14] J. Payne, "Responding to the consumers' desire for improved hygiene with antibacterial plastics," Polymers and Polymer Composites, vol. 12, no. 2, pp. 135-142, 2004.

[15] M. Marini, S. De Niederhausern, R. Iseppi et al., "Antibacterial activity of plastics coated with silver-doped organic-inorganic hybrid coatings prepared by sol-gel processes," Biomacromolecules, vol. 8, no. 4, pp. 1246-1254, 2007.

[16] H. Z. Zhang, Z. C. He, G. H. Liu, and Y. Z. Qia, "Properties of different chitosan/low-density polyethylene antibacterial plastics," Journal of Applied Ploymer Science, vol. 113, no. 3, pp. 2018-2021, 2009.

[17] L. Li-Hsiang, C. Shih-Chung, W. Ching-Zong, H. Jing-Ming, and $\mathrm{O}$. Keng-Lia, "Microstructure and antibacterial properties of microwave plasma nitrided layers on biomedical stainless steels," Applied Surface Science, vol. 257, no. 17, pp. 7375-7380, 2011.

[18] N. F. Atta, A. M. Fekry, and H. M. Hassaneen, "Corrosion inhibition, hydrogen evolution and antibacterial properties of newly synthesized organic inhibitors on 316L stainless steel alloy in acid medium," International Journal of Hydrogen Energy, vol. 36, no. 11, pp. 6462-6471, 2011.

[19] W. Hefeng, T. Bin, L. Xiuyan, and M. Yong, "Antibacterial properties and corrosion resistance of nitrogen-doped $\mathrm{TiO}_{2}$ coatings on stainless steel," Journal of Materials Science \& Technology, vol. 27, no. 4, pp. 309-316, 2011.

[20] L. Ren, L. Nan, and K. Yang, "Study of copper precipitation behavior in a Cu-bearing austenitic antibacterial stainless steel," Materials and Design, vol. 32, no. 4, pp. 2374-2379, 2010.

[21] K. Page, M. Wilson, and I. P. Parkin, "Antimicrobial surfaces and their potential in reducing the role of the inanimate environment in the incidence of hospital-acquired infections," Journal of Materials Chemistry, vol. 19, no. 23, pp. 3819-3831, 2009.

[22] Q. Li, R. C. Xie, Y. W. Li, E. A. Mintz, and J. K. Shang, "Enhanced visible-light-induced photocatalytic disinfection of $\mathrm{E}$. coli by carbon-sensitized nitrogen-doped titanium oxide," Environmental Science and Technology, vol. 41, no. 14, pp. 50505056, 2007.

[23] F. N. Chen, X. D. Yang, F. F. Xu, Q. Wu, and Y. P. Zhang, "Correlation of photocatalytic bactericidal effect and organic matter degradation of $\mathrm{TiO}_{2}$ Part I: observation of phenomena," Environmental Science and Technology, vol. 43, no. 4, pp. 1180-1184, 2009.

[24] S. Silver and L. T. Phung, "Bacterial heavy metal resistance: new surprises," Annual Review of Microbiology, vol. 50, pp. 753-789, 1996.

[25] V. Sambhy, M. M. MacBride, B. R. Peterson, and A. Sen, "Silver bromide nanoparticle/polymer composites: dual action tunable antimicrobial materials," Journal of the American Chemical Society, vol. 128, no. 30, pp. 9798-9808, 2006.

[26] H. Y. Lee, H. K. Park, Y. M. Lee, K. Kim, and S. B. Park, "A practical procedure for producing silver nanocoated fabric and its antibacterial evaluation for biomedical applications," Chemical Communications, vol. 2007, pp. 2959-2961, 2007.

[27] M. Es-Souni, H. Fischer-Brandies, and M. Es-Souni, "Versatile nanocomposite coatings with tunable cell adhesion and bactericidity," Advanced Functional Materials, vol. 18, no. 20, pp. 3179-3188, 2008.

[28] D. W. Sheel, L. A. Brook, I. B. Ditta et al., "Biocidal silver and silver/titania composite films grown by chemical vapour deposition," International Journal of Photoenergy, vol. 2008, Article ID 168185, pp. 1-11, 2008.

[29] L. Mai, D. Wang, S. Zhang, Y. Xie, C. Huang, and Z. Zhang, "Synthesis and bactericidal ability of $\mathrm{Ag} / \mathrm{TiO}_{2}$ composite films deposited on titanium plate," Applied Surface Science, vol. 257, no. 3, pp. 974-978, 2010.

[30] M. J. Santillán, N. E. Quaranta, and A. R. Boccaccini, “Titania and titania-silver nanocomposite coatings grown by electrophoretic deposition from aqueous suspensions," Surface and Coatings Technology, vol. 205, no. 7, pp. 2562-2571, 2010.

[31] L. Y. Chai, Y. F. Yu, G. Zhang, B. Peng, and S. W. Wei, "Effect of surfactants on preparation of nanometer $\mathrm{TiO}_{2}$ by pyrohydrolysis," Transactions of Nonferrous Metals Society of China, vol. 17, no. 1, pp. 176-180, 2007.

[32] S. W. WEI, B. PENG, L. Y. CHAI, Y. C. LIU, and Z. Y. LI, "Preparation of doping titania antibacterial powder by ultrasonic spray pyrolysis," Transactions of Nonferrous Metals Society of China, vol. 18, no. 5, pp. 1145-1150, 2008.

[33] L. Y. CHAI, S. W. WEI, B. PENG, and Z. Y. Li, "Adsorption of $\mathrm{Ag}(\mathrm{I})$ on $\mathrm{H}_{2} \mathrm{TiO}_{3}$ from aqueous solutions," Transactions of Nonferrous Metals Society of China, vol. 17, no. 4, pp. 832-835, 2007.

[34] L. Y. Chai, W. F. Su, B. Peng et al., "Modification of nano- $\mathrm{TiO}_{2}$ by $\mathrm{Al}_{2} \mathrm{O}_{3}$ in-situ coating," Journal of Central South University of Technology, vol. 13, no. 1, pp. 17-21, 2006.

[35] L. Y. Chai, S. W. Wei, B. Peng, and Z. Y. Li, "Effect of thermal treating temperature on characteristics of silver-doped titania," Transactions of Nonferrous Metals Society of China, vol. 18, no. 4, pp. 980-985, 2008. 


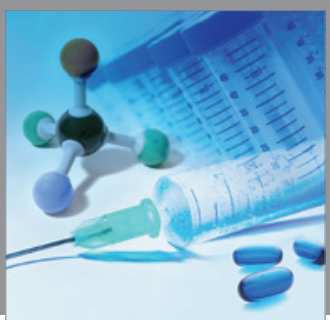

International Journal of

Medicinal Chemistry

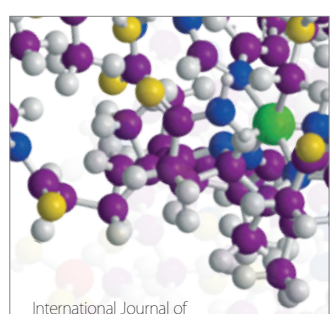

Carbohydrate Chemistry

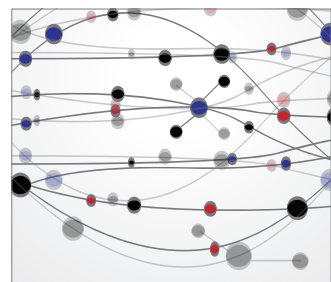

The Scientific World Journal
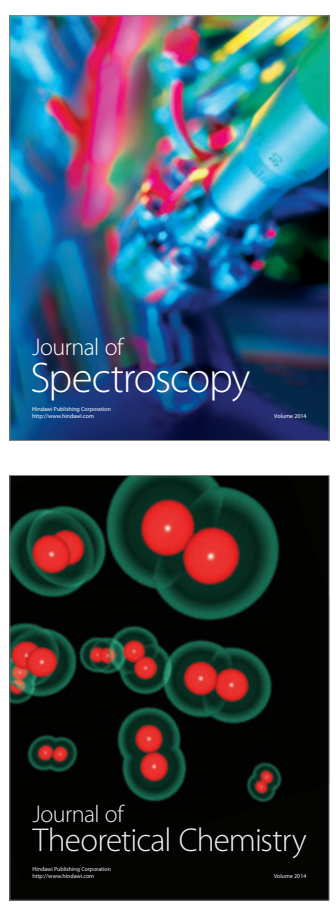
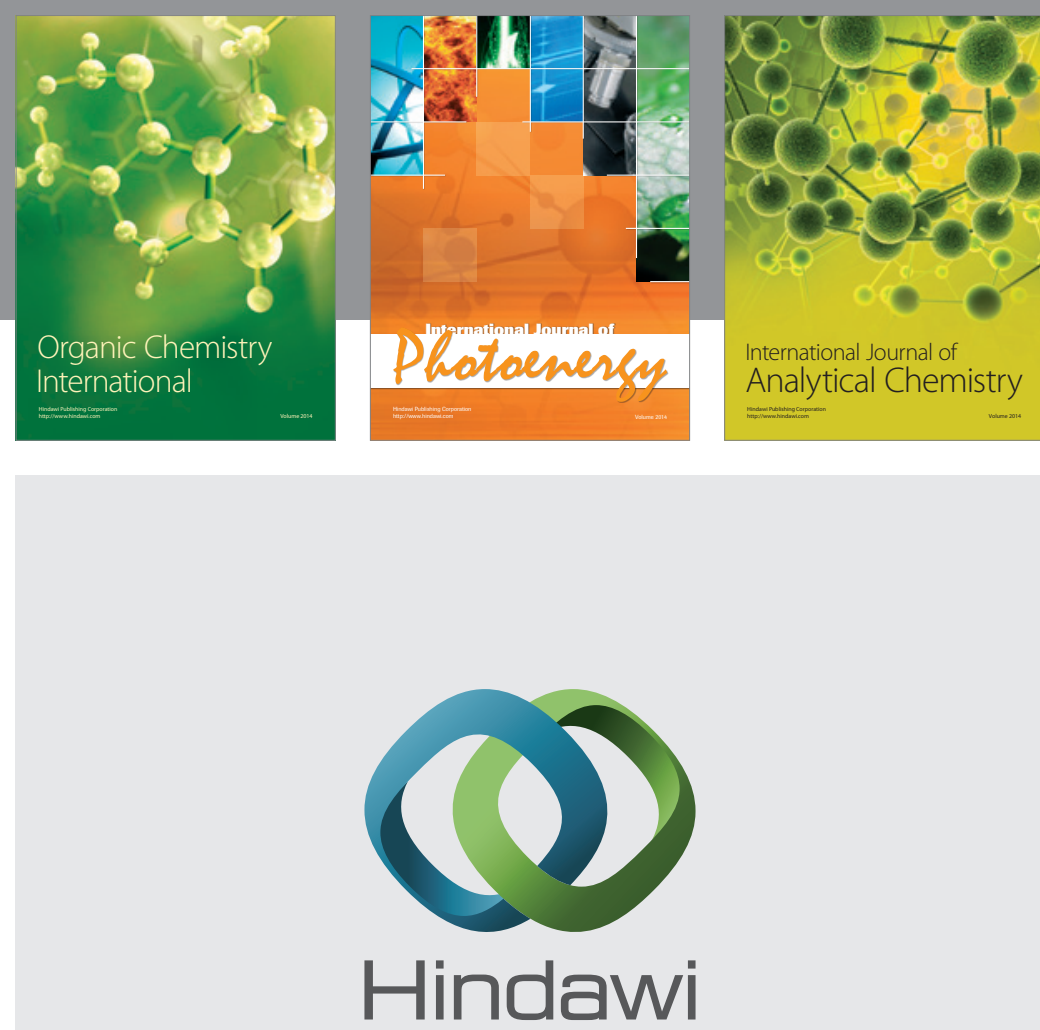

Submit your manuscripts at

http://www.hindawi.com
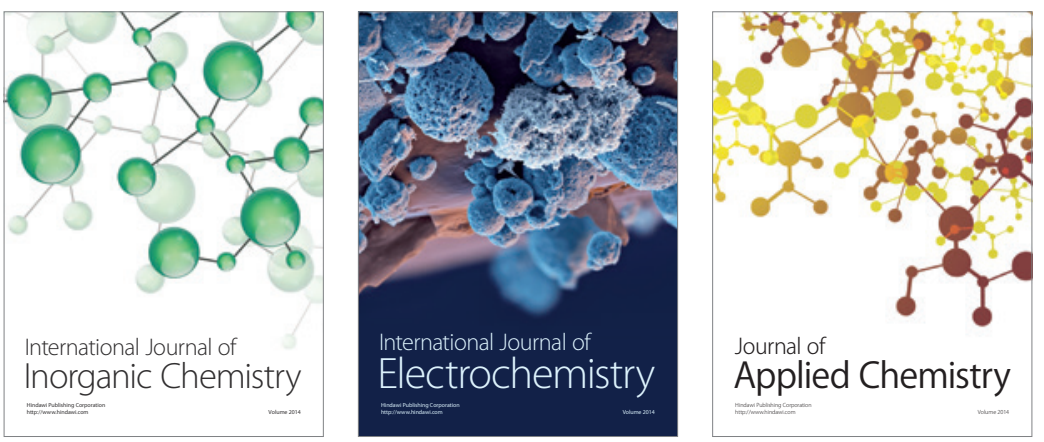

Journal of

Applied Chemistry
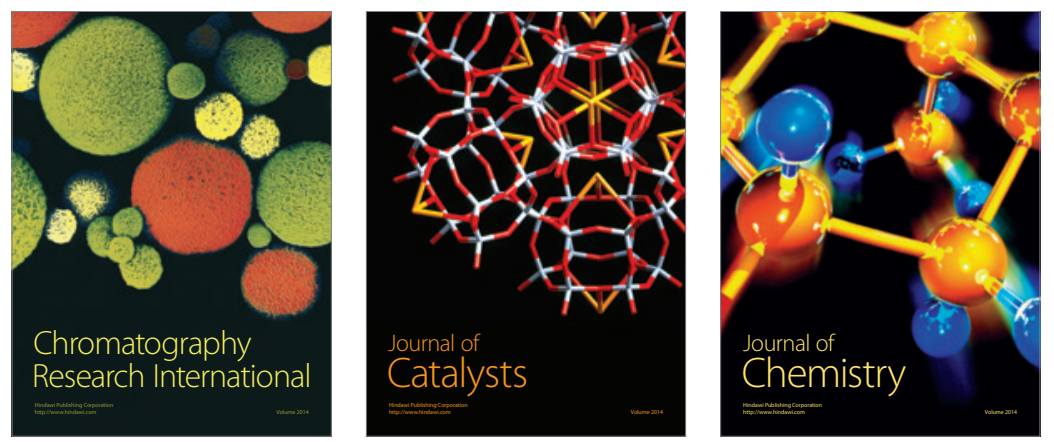
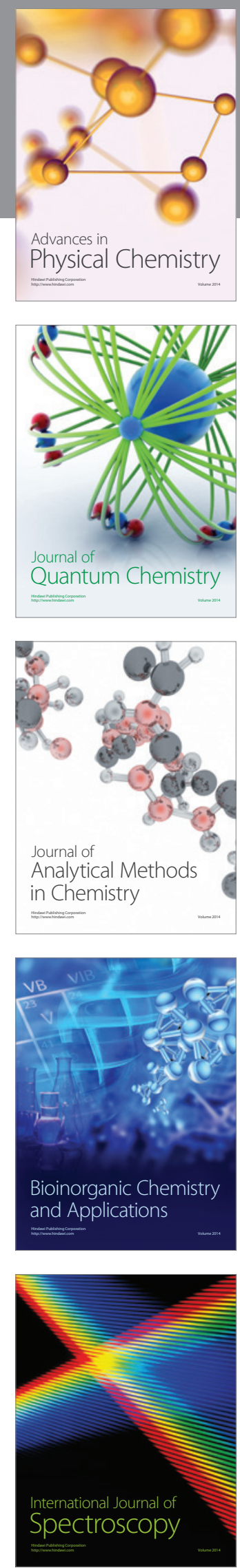